false lumen abruptly increased (62\% to $82 \%$ ) in case of thoracic or thoracoabdominal aneurysm at the moment of dissection. The concept of endotension because of unobservable endoleak and pressure transmittance through the thrombus has recently been suggested as a cause of this phenomenon. ${ }^{7}$ Leaks may also occur at the ends of the stent graft or may result from retrograde filling from an aortic branch. Finally, extension and quality of landing zone are very important issues to prevent endoleak. Because many type $\mathrm{B}$ aortic dissections have primary entry tears cross to the orifice of the left subclavian artery, bending of the stent graft at the small curvature of the aortic arch shows a high risk of endoleak or retrograde dissection. From a surgeon's point of view, it is important to know that an acute retrograde aortic dissection after an initial type B dissection may occur during, shortly after, or even late after an implantation of an endovascular stent graft. Surgical treatment in this setting crucially depends on the anatomic location of the endovascular stent in relation to the aortic arch and arch vessels. The elephant trunk procedure seems to be particularly useful in this type of dissection. ${ }^{8}$ In conclusion, endovascular treatment of aortic aneurysms and dissection is an effective and promising option, but technical improvements and better patient selection are mandatory to avoid dangerous complications necessitating high-risk surgery.

\section{References}

1. Elefteriades JA, Hartleroad J, Gusberg RJ. Long-term experience with descending aortic dissection: the complication specific approach. Ann Thorac Surg. 1992;53:11-21.

2. Coselli JS, Lemaire SA, Miller CC. Mortality and paraplegia after thoracoabdominal aneurysm repair: a risk factor analysis. Ann Thorac Surg. 2000;69:409-14.

3. Svensson LG, Crawford ES, Hess KR. Experience with 1509 patients undergoing thoracoabdominal aortic operations. J Vasc Surg. 1993;17: 357-63.

4. Dake MD, Kato N, Mitchell RS. Endovascular stent-graft placement for the treatment of acute aortic dissection. N Engl J Med. 1999;340:154652.

5. Nienaber CA, Fattori R, Lund G, et al. Non surgical reconstruction of thoracic aortic dissection by stent-graft placement. $N$ Engl $\mathrm{J} \mathrm{Med.}$ 1999;340:1539-45.

6. Shimono T, Kato N, Yasuda F, et al. Transluminal stent-graft placements for the treatments of acute onset and chronic aortic dissections. Circulation. 2002;106(suppl 1):I241-7.

7. Gilling-Smith G, Brennan J, Harris P. Endotension after endovascular aneurysm repair: definition, classification, and strategies for surveillance and intervention. J Endovasc Surg. 1999;6:305-7.

8. Totaro M, Miraldi F, Fanelli F, Mazzesi G. Emergency surgery for retrograde extension of type B dissection after endovascular stent graft repair. Eur J Cardiothorac Surg. 2001;20:1057-8.

\title{
Venous embolization during sternotomy in children undergoing corrective heart surgery
}

\author{
Ilan Keidan, MD, ${ }^{\text {a }}$ Yael Mardor, PhD, ${ }^{\mathrm{b}}$ Sergei Preisman, MD, ${ }^{\mathrm{a}}$ and David Mishaly, MD, ${ }^{\mathrm{c}}$ Tel Aviv, Israel
}

$\mathrm{G}$ as embolism results from a negative pressure gradient between veins exposed to air and the central venous pressure. ${ }^{1}$ The incidence varies according to the procedure, the position, and the detection method used. Venous air embolism (VAE) in cardiac surgery has been previously observed during central venous cannulation and while opening the heart chambers during cardiopulmonary bypass. ${ }^{2}$ We now describe, for the first time, the detection of VAE by transesophageal echocardiography during sternotomy in children undergoing

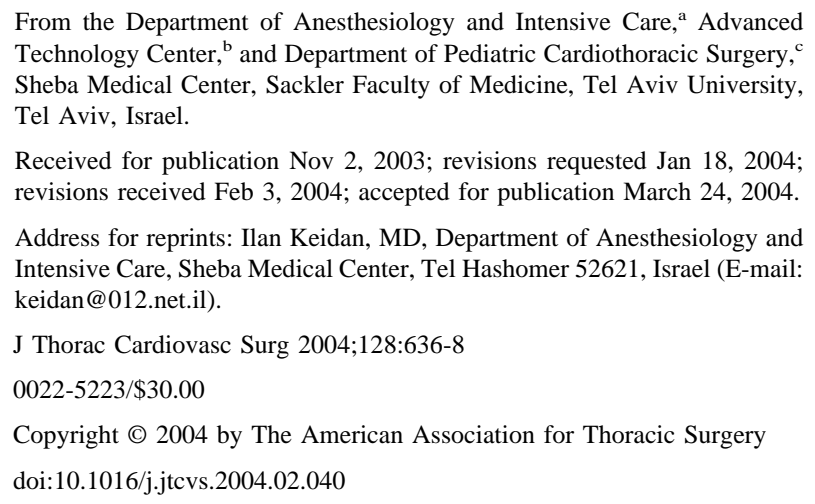

Received for publication Nov 2, 2003; revisions requested Jan 18, 2004; revisions received Feb 3, 2004; accepted for publication March 24, 2004.

Address for reprints: Ilan Keidan, MD, Department of Anesthesiology and Intensive Care, Sheba Medical Center, Tel Hashomer 52621, Israel (E-mail: keidan@012.net.il).

J Thorac Cardiovasc Surg 2004;128:636-8

$0022-5223 / \$ 30.00$

Copyright $\odot 2004$ by The American Association for Thoracic Surgery

doi:10.1016/j.jtcvs.2004.02.040

corrective heart surgery. In addition, we show that sternotomy with scissors significantly reduces the risk of embolization compared with using a saw.

\section{Patients and Methods \\ Patients}

Twenty children scheduled for corrective heart surgery were enrolled. Patients with a previous sternotomy were excluded. Patients were randomly assigned to the saw or scissors group. Ten children who underwent sternotomy with a saw had a ventricular septal defect $(n=2)$, total anomalous pulmonary venous return $(n=1)$, tetralogy of Fallot $(n=1)$, truncus arteriosus $(n=1)$, mitral stenosis $(n=1)$, or double-outlet right ventricle $(n=1)$. The other 10 children who underwent sternotomy with scissors had an atrial septal defect $(n=2)$, ventricular septal defect $(n=2)$, tetralogy of Fallot $(n=2)$, total anomalous pulmonary venous return $(n=1)$, hypoplastic left heart syndrome $(n=1)$, transposition of the great arteries $(\mathrm{n}=1)$, and cor triatriatum $(\mathrm{n}=1)$.

\section{Monitoring}

Monitoring included electrocardiogram, pulse oximetry, end-tidal carbon dioxide, invasive arterial blood pressure, and central venous pressure. During sternotomy, patients were disconnected from the ventilator, and no fluids or medications were infused. 


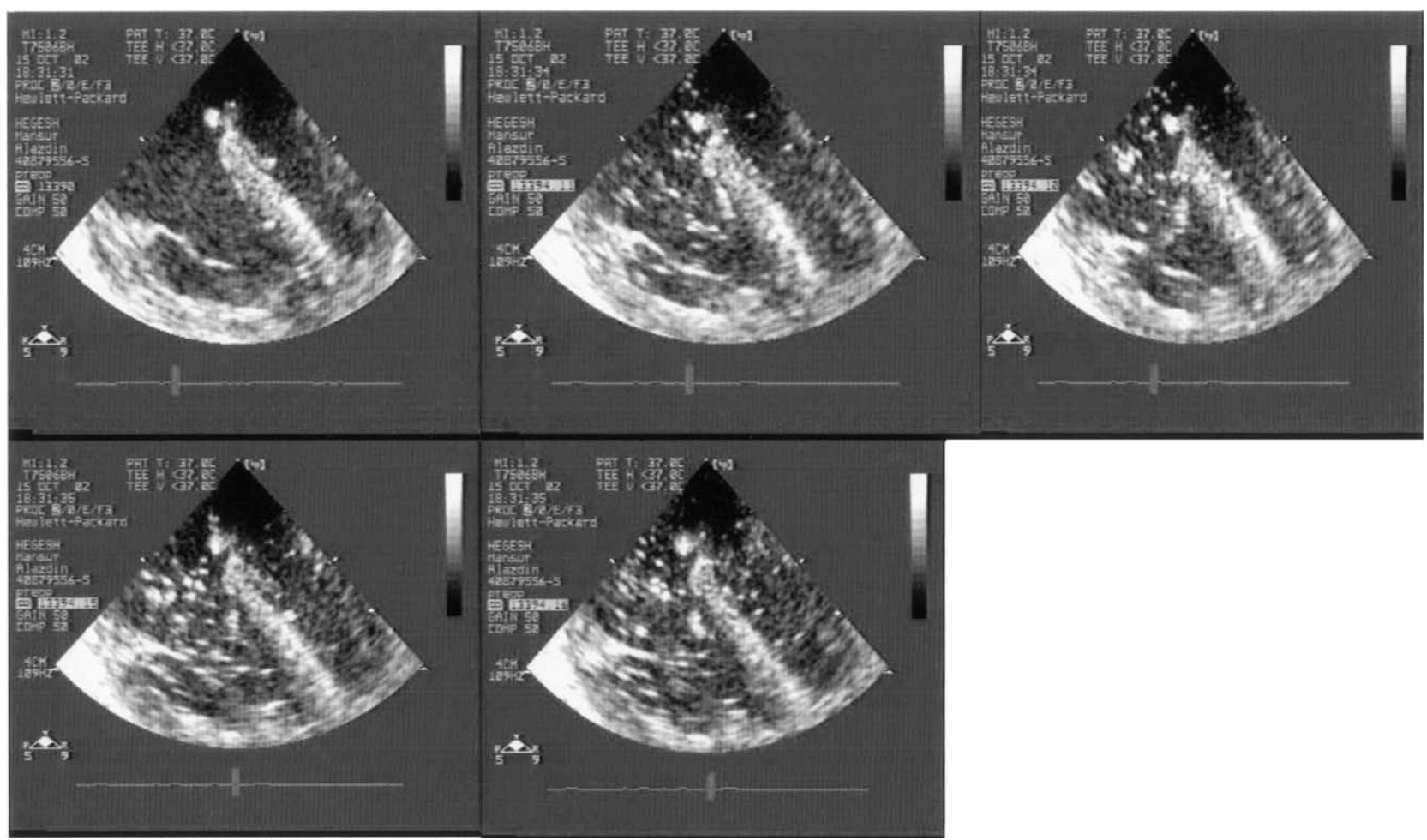

Figure 1. Transesophageal echocardiography images before and during sternotomy in a neonate with total anomalous pulmonary venous return.

\section{Echocardiography}

A 4-chamber view of the heart was obtained by a $5.0-\mathrm{MHz}$ multiplane transesophageal echocardiography transducer (SONOS 5500; Hewlett-Packard, Andover, Mass). The transducer was positioned so that the right atrium was in the center of the screen. Data were recorded by a videotape.

\section{Data Analysis}

The number of VAEs was assessed qualitatively, per patient, by 3 pediatric cardiologists with clinical experience in intraoperative echocardiography. They were blinded to the method of sternotomy. The VAEs detected for each patient were defined on a scale of 0 to 3 , where 0 indicated no targets, 1 indicated occasional targets, 2 indicated many targets, and 3 indicated targets filling the entire atrium. ${ }^{2}$ The results of the 3 echocardiographic evaluations were averaged per patient, and a comparison between groups was performed by using the Mann-Whitney rank sum test.

\section{Results}

VAEs were detected in $14(70 \%)$ patients. Most emboli were small $(<2 \mathrm{~mm})$ and appeared similar to the microbubbles produced by agitating saline with a small amount of air (Figure 1). The incidence was significantly higher $(P<.002)$ when sternotomy was performed with a saw compared with scissors (Table 1). The peak number of emboli appeared approximately 5 seconds after sternotomy and returned to baseline at the end of the procedure. Six patients also had larger $(>5 \mathrm{~mm})$ emboli that appeared to be solid material. Passage of emboli to the left cardiac chambers was
TABLE 1. Comparison of intracardiac emboli between children undergoing sternotomy with a saw versus scissors

\begin{tabular}{lcc}
\hline Variable & Saw $(\mathbf{n}=\mathbf{1 0})$ & Scissors $(\mathbf{n}=\mathbf{1 0})$ \\
\hline Intracardiac embol vs & $1.90 \pm 0.83^{*}$ & $0.41 \pm 0.46$ \\
scale (mean \pm SD) & & \\
Median & 2.0 & 0.33 \\
Lower 95\% Cl & 1.3 & 0.02 \\
Upper 95\% Cl & 2.49 & 0.80
\end{tabular}

$\mathrm{Cl}$, Confidence interval.

${ }^{*} P<.002$; Mann-Whitney rank sum test.

detected in 5 patients $(25 \%)$ with a known right-to-left shunt and in whom sternotomy was performed with a saw. No significant hemodynamic changes or changes in end-tidal carbon dioxide or arterial saturation between preprocedure and postprocedure values were detected.

\section{Discussion}

Children are less prone to VAE than adults, but they are more susceptible to the side effects, especially when a right-to-left shunt exists. ${ }^{3}$ The incidence of VAE increases when a vein that cannot collapse is opened, ${ }^{4}$ such as the cranial diploic veins. Other risk factors for VAE are large airway pressure variations, which were shown to decrease venous pressure to subatmospheric levels. ${ }^{5}$ The same risk factors were present in our study population: opening of 
the sternum veins bears some similarity to the opening of the cranial vault veins, and disconnecting the endotracheal tube just before sternotomy decreases airway pressure. Furthermore, 5 $(25 \%)$ of our patients had a preexisting right-to-left shunt, again increasing the likelihood of clinically significant VAE. The fact that embolus incidence was higher with the saw compared with the scissors is not straightforward. It would seem that the saw would result in less compression of the bone marrow, thus being less traumatic. One may hypothesize that the vibration caused by the saw action induces microbubble formation such as in agitated saline. This hypothesis was tested by pressing the saw against the closed chest wall, thus testing the effects of the vibrations alone. No emboli were detected. Another explanation might be that the vibrations cause increased small amounts of air entrainment in the open vessels. This hypothesis has not been tested. In summary, our results suggest that VAE during sternotomy is a frequent occur- rence and that the number of emboli is related to the method of sternotomy.

\section{References}

1. Albin MS, Carroll RG, Maroon JC. Clinical considerations concerning detection of venous air embolism. Neurosurgery. 1978;3:380-4.

2. Propst JW, Siegel LC, Schnittger I, Foppiano L, Goodman SB, BrockUtne JG. Segmental wall motion abnormalities in patients undergoing total hip replacement: correlations with intraoperative events. Anesth Analg. 1993;77:743-9.

3. Bracco D, Bissonnette B. Neurosurgery and neuro traumatology: anesthetic considerations and postoperative management. In: Bissonnette B, Dalens B, editors. Pediatric anesthesia: principles and practice. New York: McGraw-Hill; 2002. p. 1130-1.

4. Palmon SC, Moore LE, Lundberg J, Toung T. Venous air embolism: a review. J Clin Anesth. 1997;9:251-7.

5. Muth CM, Shank ES. Gas embolism. N Engl J Med. 2000;342:476-82.

\title{
First human transplantation of a bioengineered airway tissue
}

\author{
Paolo Macchiarini, MD, PhD, ${ }^{\mathrm{a}, \mathrm{b}}$ Thorsten Walles, MD, ${ }^{\mathrm{a}, \mathrm{b}}$ Christian Biancosino, ${ }^{\mathrm{b}}$ and Heike Mertsching, PhD, \\ Hannover, Germany
}

A irway defects occurring at the anastomotic site after carinal pneumonectomy are associated with persistent contamination between airway and pleural spaces, mediastinal spaces, or both and difficulties in the re-expansion of and possible aspiration into the residual lung. Unfortunately, therapeutic interventions are limited, and the outcome is often fatal. ${ }^{1}$ An ideal solution would be to generate an airway segment or surface to be implanted after achieving control of the infection and aspiration. Tissue-engineered airway is about the only technique of the many attempts at tracheal replacement that seems to offer any real promise. ${ }^{2}$ It applies the principles of engineering and life sciences toward the development of biologic substitutes that restore, maintain, or improve tissue function and offers the potential to create replacement structures from biode-

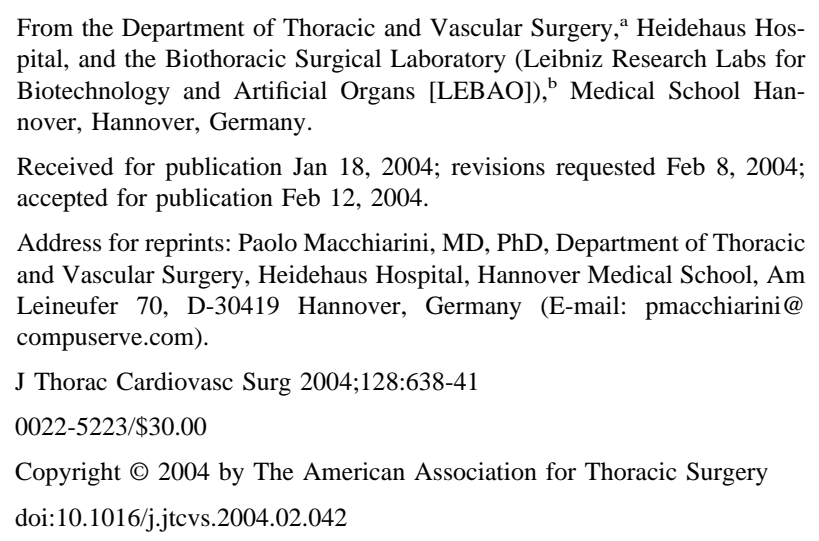

gradable scaffolds and autologous cells. ${ }^{3}$ We here describe the first clinical application of a tissue engineered airway patch.

\section{Clinical Summary}

A 58-year-old man was admitted in April 2003 complaining of general weakness, coughing up of pus, temperature of greater than $39^{\circ} \mathrm{C}$, shortness of breath, and intolerable halitosis. He had undergone a right completion carinal pneumonectomy and radical lymphadenectomy for a relapsing non-small cell lung cancer pathologically staged as T4 N0 M0 in March 2003. He had had an upper bilobectomy and adjuvant radiation therapy (60 Gy) for an non-small cell lung cancer of equal histotype staged as T3 N2 in 1999. On chest radiography, the air-fluid pleural level in the postpneumonectomy space vanished, and the contralateral left lower lobe showed infiltrative signs suggestive of aspiration pneumonitis. Bronchoscopy showed a complete dehiscence of the ventrolateral aspect of the tracheobronchial anastomosis measuring 2 $\times 2 \mathrm{~cm}$, communicating directly with the residual pleural space. Because Pseudomonas aeruginosa strains were found in the pleural space and blood, the diagnosis of pleural empyema and pyosepticemia was made, and the decision was taken to perform both ventral and dorsal open thoracostomies. The patient was further treated medically with the intent to sterilize the residual pleural space, prevent bacterial contamination of the residual left lung, and obtain a spontaneous closure of the anastomotic dehiscence.

The patient's general conditions improved slowly to an extent that his pleural space was uncontaminated, and his pyosepticemia resolved. However, on the basis of the previous bad clinical experiences, ${ }^{1}$ written informed consent was obtained to take, after 